\title{
A Comparative Study of Global Software Development Tools Supporting Project Management Activities
}

\author{
Hafiz Anas Bilal, ${ }^{\mathrm{a},}$, Sunnia Amjad ${ }^{\mathrm{a}}$, and Muhammad Ilyas ${ }^{\mathrm{b}}$ \\ ${ }^{a}$ Department of Computer Science, COMSATS Institute of Information Technology, Islamabad, Pakistan \\ ${ }^{b}$ Department of Computer Science \& IT, University of Sargodha, Sargodha, Pakistan
}

Received: 10 September 2016; Accepted: 23 November 2016; Published: 08 November 2017

\begin{abstract}
For the last few years, Global Software Development (GSD) has been gaining attention of experts and researchers. Because of distance, communication and cultural issues GSD is creating hurdles for performing effective project management. In this regard, GSD provides a large number of tools and technologies to facilitate and simplify the work for project managers. To accomplish this task we have used a framework. The results of the study of 21 existing tools reveals that although GSD tools show dominating strengths in achieving some Project Management (PM )goals, yet much work needs to be done. Comprehensively, there is an ultimate need of a single GSD that could facilitate every aspect of PM.
\end{abstract}

Index Terms: Global Software Development, Global Project Management, GSD Tools.

(C) 2017 Published by MECS Publisher. Selection and/or peer review under responsibility of the Research Association of Modern Education and Computer Science.

\section{Introduction}

Distributed software development is becoming prevalent day by day and this substantial increase in its popularity is imposing many professionals to do projects in distributed fashion. Improved quality, lower cost, high productivity, reduced time to market, higher customer satisfaction etc. are the factors behind its popularity among professionals [1]. This increasing popularity of globalization creates a number of challenges and problems for professionals [2]. Software project management is one of the major difficult and challenging tasks in a globally distributed environment. [3].

Possible benefits and problems of GSD are large in number and it needs an effective project management to successfully implement the distributed application. [4], that effective project management is actually the project

\footnotetext{
* Corresponding author.
}

E-mail address: 
planning and organizational design in GSD [5] [6]. In this regard effective GSD tools supporting PM will be a big relief.

This paper aims on the study of the GSD tools that support an effective PM support. The work of [7] has presented a framework for PM in GSD. This model covers the global PM and communication with globally distributed development team therefore it can be used as a criteria against which existing tools can be judged. Then 21 existing tools are measured against our defined criteria. Afterwards, analysis is performed to find some important results. Although GSD tools shows dominating strengths in achieving some project management goals, but sill much work needs to be done. Comprehensively there is an ultimate need of a single project management tool that could facilitate every aspect of GSD.

This paper is decomposed into the following sections. Section 2 describes the literature review; section 3 presents the methodology adopted for this study. Section 4 covers result of study and in section 5 some results and findings are enlisted. Then finally the paper sums up with the conclusion in Section 6.

\section{Literature Review}

According to Binder, only few of the organizations have established effective strategies and practices for supporting effective project management [8]. In addition, Pichler reports that ignoring the distribution problems, many teams are created in a way that they just have to work at only one site even in a distributed environment [9]. Moreover, in Komi-Sirviö and Tihinen view high cost, low quality, low productivity, increased market time, high risks, lack of communication and coordination etc. are the major issue in GSD environment and are difficult to address. Hence, there is a need of effective managerial approach or PM tools in order to reduce these problems [10]. According to Kraut and Streeter, global distribution is increasing its complexity as people are unable to manage the coordination problems [11]. In Ansgar and Jürgen's view, proper project management strategy is required to solve GSD problems such as deficiency of informal communication [13], deficiency of trust among teams [14], time differences [15], or cultural variances [16] [12].

Author's views clearly show the importance of project management in GSD. Tools will definitely make this task easier to perform. We also did a literature review on GSD tools supporting project management activities.

The work of Javier, Aurora and Sarah covers the communication aspect of GSD tools. It has not only presented a comprehensive study of existing GSD tools but has also classified them. [17]. Martignoni focused the tools and services for GSD among globally distributed teams. It covers the classification of GSD tools according to different phases of software development [18]. Portillo, Vizcaino, Ebert and Piattini did a survey of GSD tools presented in [19] focused ISO/IEC 12207. The features offered by existing GSD tools are compared against the criteria defined in GSD standard set by ISO/IEC [19]. the research conducted by Filippo, Christof, Rafael, Vizcaino and Aurora cover collaboration aspect of GSD teams. The features of existing collaborative environments are analyzed to support GSD [20].

\section{Methodology}

To examine the existing GSD tools, it is essential to define the criteria to measure them. Since the primary focus of this paper is to measure PM capabilities of a GSD tool, there must be a PM framework for GSD. The work of [7] has presented a comprehensive framework for process of PM to be followed in GSD. The framework of [7] is therefore selected as criteria to review existing GSD tools. This framework covers two major goals.

Goal 1: The management of a project in global context.

Goal 2: Administration across various GSD sites. 
Table 1. Goal 1 with its Sub-Goals and their Practices

\begin{tabular}{|c|c|c|}
\hline \multirow{12}{*}{$\begin{array}{c}\text { Goal 1: The management of a project } \\
\text { in global context }\end{array}$} & \multirow[t]{2}{*}{ Management of a task globally } & Define team structure \\
\hline & & Task allocation \\
\hline & \multirow{4}{*}{ Team members' proficiency management } & Determine business skills \\
\hline & & Define cultural desires of every team \\
\hline & & Communication strategies \\
\hline & & Identifying training criteria \\
\hline & \multirow{6}{*}{ Administering PM globally } & Determining PM tasks \\
\hline & & Task allocation \\
\hline & & Focus cultural concerns of teams \\
\hline & & Determine collaboration policies \\
\hline & & Define reporting criteria \\
\hline & & Risk management \\
\hline
\end{tabular}

Table 2. Goal 2 with its Sub-Goals and their Practices

\begin{tabular}{|c|c|c|}
\hline \multirow{8}{*}{$\begin{array}{c}\text { Goal 2: Administration across } \\
\text { various GSD sites }\end{array}$} & \multirow{4}{*}{ Procedures for project execution } & Conflicts management \& resolution \\
\hline & & Define collaboration procedures \\
\hline & & Define coordination interface \\
\hline & & Determine meeting policies \\
\hline & \multirow{4}{*}{ Managing coordination across GSD teams } & Define project vision and incentives \\
\hline & & Determine scope of project and assign roles \\
\hline & & Enforce procedures to maintain interfaces \\
\hline & & $\begin{array}{l}\text { Effective coordination and dissemination } \\
\text { of information }\end{array}$ \\
\hline
\end{tabular}

The main focus of this research is to find the extent to which the existing tools meet Goal 1 and Goal 2. It is important to note that there are many GSD tool available in market. In terms of PM there are several tools facilitating some aspects of PM. Therefore the focus in on those tools supporting GSD and offering some sort of PM feature. For this research 21 such tools are studied and evaluated against the chosen criteria.

\section{Comparative Study}

In table 1 , all tools are mentioned with their short names which we will use in mapping in figure $2 \& 3$. The comparison of tools is shown in figure 2 and 3 below. In figure 2, goal 1, its sub-goals and their corresponding practices are displayed. While in figure 3 , goal 2 is represented with its corresponding sub-goals and practices.

Table 3. List of Selected Tools with Their Acronyms

\begin{tabular}{llllll}
\hline Sr. \# & Tool Name & & Sr. \# & Tool Name & ASEM \\
\hline 1. & ActiveCollab [30] & AC & 2. & Assembla [31] & CBMR \\
3. & CollabVS [31] & CVS & 4. & codeBeamer [21] & GS \\
5. & COMINDWORK [24] & CWRK & 6. & Gatherspace [25] & AGR \\
7. & ADAMS [34] & ADM & 8. & Augur [35] & DPR \\
9. & Bugzilla [33] & BZL & 10. & DrProject [36] & IPL \\
11. & Fonseca [37] & FNC & 12. & IssuePlayer [36] & MBT \\
13. & Jira [32] & JR & 14. & MantisBT [26] & NMV \\
15. & Maven [22] & MVN & 16. & NextMove [38] & TMS \\
17. & TAMRI [12] & TMR & 18. & Teamness [28] & WAV \\
19. & Trac [23] & TRC & 20. & WorkspaceActivityViewer [27] & \\
21. & HOBBES [39] & HBS & & & \\
\hline
\end{tabular}




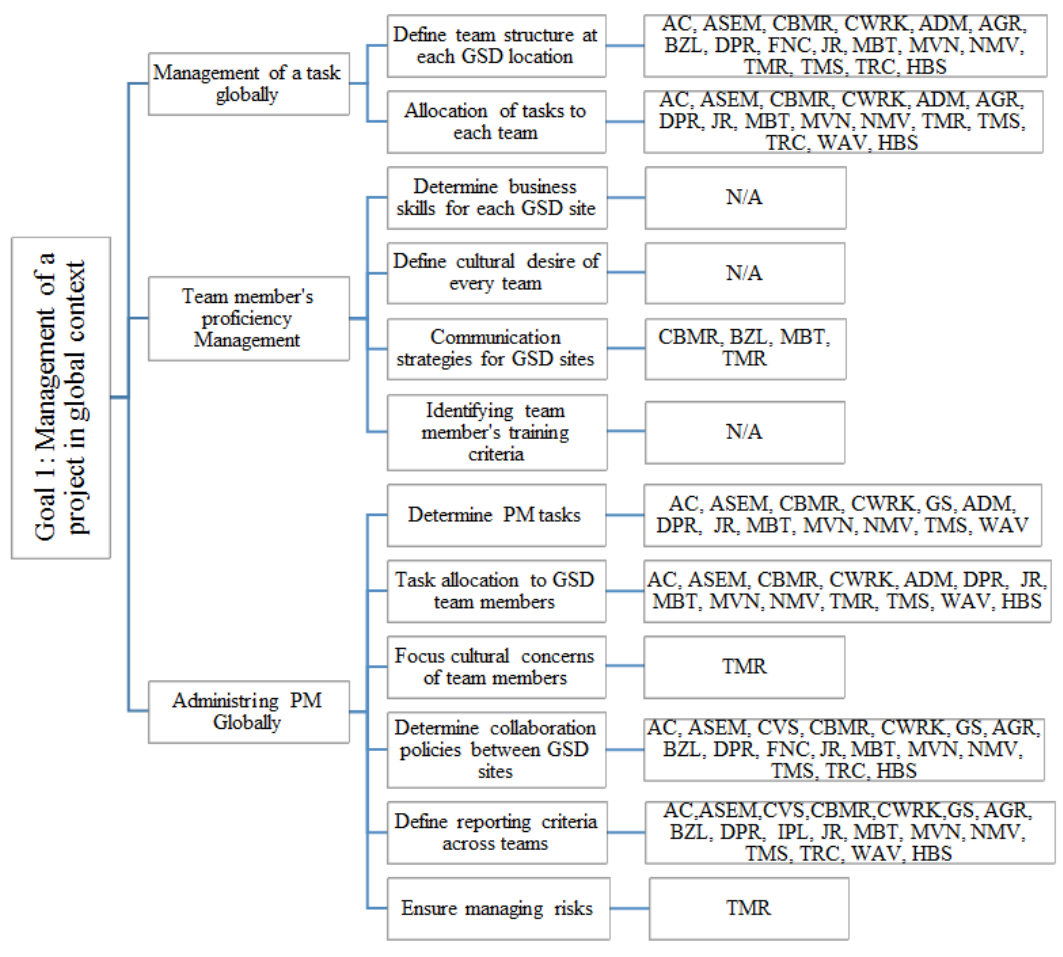

Fig.1. Mapping of Goal 1, its Sub-Goals and Their Corresponding Practices with GSD Tools

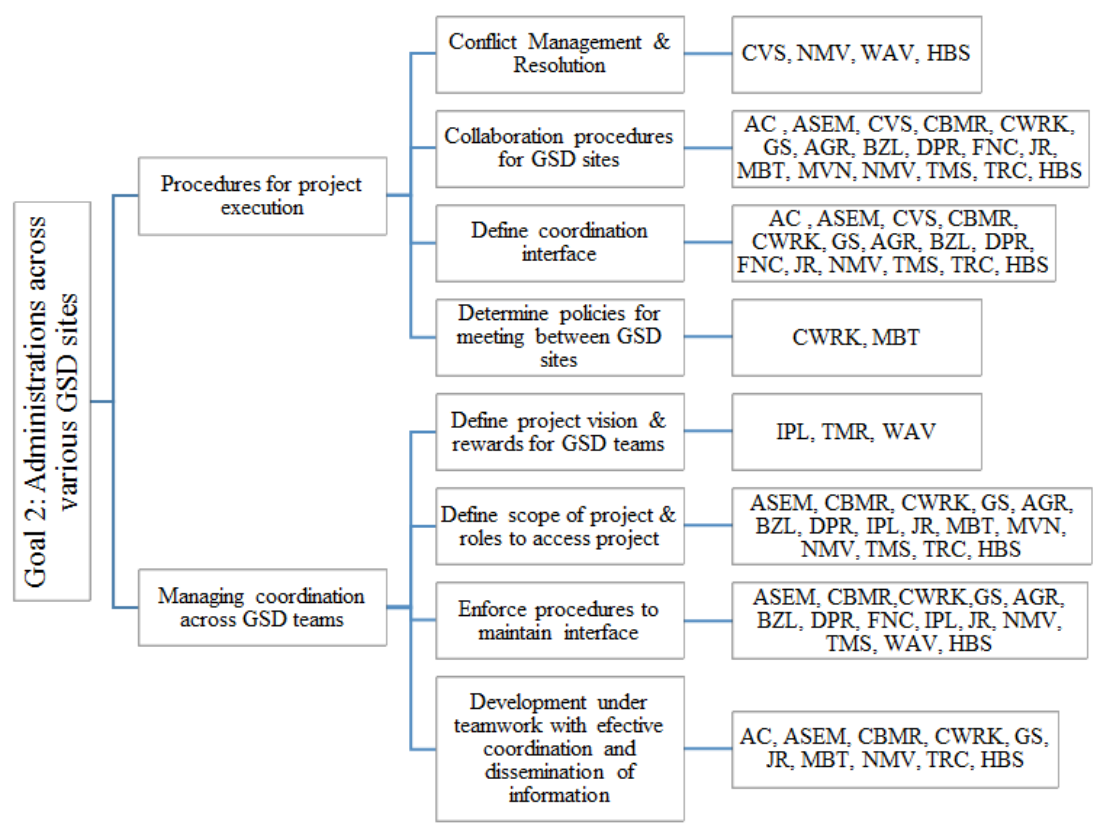

Fig.2. Administration across Various GSD Sites 


\section{Results}

The review of tools in section 4 has been quantified for detailed analysis and for finding some interesting results. Each sub-goal has been assigned a score "1". Therefore summing up features of each tool Table 1 is obtained. Using this table two plots are generated, Figure 2 shows percentage of available and unavailable features for goal 1 . Blue color shows availability of a feature whereas red color shows non availability of a particular feature. Figure 3 shows goal coverage of each tool for goal 2. Blue bar shows coverage score of Goal 1 whereas red bar shows coverage score of Goal 2.

- The existing tools covers a maximum of $60 \%$ of total features reported in figure 2, remaining $40 \%$ features still needs to be the a part of them as shown in figure 2 .

- Features like conflict resolution, implementation of meeting strategy, risk and cultural profiles are the features offered by limited number of the existing tools.

- Business competency and training of team members are the features available in none of the existing tools.

- In term of features, it has been noted that some tools are strong in PM activities whereas some tools are strong at collaboration of teams. Similarly for PM activities some tools covers task allocation and tracking, some covers configuration management, some covers bug tracking and visualization. There is not a single tool offering all PM activities collectively for GSD.

Table 4. Quantification of Each Tool

TOOLS

GOAL 1

GOAL 2

\begin{tabular}{|c|c|c|}
\hline ACTIVECOLLAB & 6 & 3 \\
\hline ASSEMBLA & 6 & 5 \\
\hline COLLABVS & 2 & 3 \\
\hline CODEBEAMER & 7 & 5 \\
\hline COMINDWORK & 6 & 6 \\
\hline GATHERSPACE & 3 & 5 \\
\hline ADAMS & 4 & 0 \\
\hline AUGUR & 4 & 4 \\
\hline BUGZILLA & 4 & 4 \\
\hline DRPROJECT & 6 & 4 \\
\hline FONSECA & 2 & 3 \\
\hline ISSUEPLAYER & 1 & 3 \\
\hline JIRA & 6 & 5 \\
\hline MANTISBT & 7 & 3 \\
\hline MAVEN & 6 & 2 \\
\hline NEXTMOVE & 6 & 6 \\
\hline TAMRI & 7 & 1 \\
\hline TEAMNESS & 6 & 4 \\
\hline TRAC & 4 & 4 \\
\hline WORKSPACE ACTIVITY VIEWER & 4 & 3 \\
\hline HOBBES & 5 & 6 \\
\hline
\end{tabular}




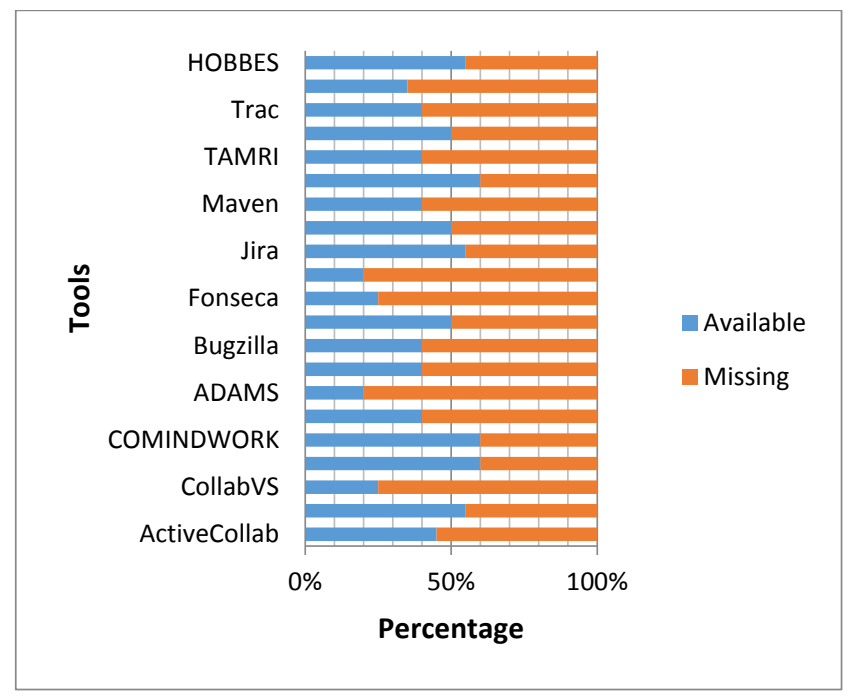

Fig.3. Percentage of Availability of Features in Each Tool

\section{Conclusions}

This paper successfully demonstrates the comparative study of 21 existing GSD tools. The findings revealed that most of the existing GSD tools fulfill the criteria of Goal 2, i.e. covering $60 \%$ of the identified sub-goals and their practices whereas Goal 1 has been covered by few tools. Most of the tools support coordination across GSD teams whereas team members' proficiency is supported by the least. Therefore the lacking features should also be focused. Similarly some tools are strong in PM features whereas some are strong at coordination and collaboration. To assist a project manager in effective global PM it is needed to have a single tool integrating all of the defined features of GSD.

\section{References}

[1] Costa C, Cunha C, Rocha R, César A. "Models and Tools for Managing Distributed Software Development: A Systematic Literature Review" in Proc. the $14^{\text {th }}$ international conference on Evaluation and assessment in Software Engineering, 2010, pp. 73-76.

[2] Ralyte J, Lamielle X, Arni-Bloch N, Leonar M. "A framework for supporting management in distributed information systems development" in Proc. Second International Conference on Research Challenges in Information Science, 2010, pp. 381-392.

[3] Casey V, Richardson I. "Project Management within Virtual Software Teams" in Proc. International Conference on Global Software Engineering, 2006, pp. 33-42.

[4] Betz S, Mäkiö. "Amplification of the COCOMO II regarding offshore software projects". Workshop on Offshoring of Software Development-Methods and Tools for Risk Management at the Second International Conference on Global Software Engineering, 2007, pp. 33-46.

[5] Herbsleb JD, Grinter RE. "Splitting the organization and integrating the code: Conway's law revisited" in Proc. the 21st International Conference on Software Engineering, 1999, pp. 85-95.

[6] Herbsleb JD. "Global software engineering: The future of socio-technical coordination" in Proc. the Future of Software Engineering, FOSE, pp.188-198, 2007.

[7] Richardson I. "A process framework for global software engineering teams" in Proc. International 
Conference on Information and Software Technology 54(11), pp. 1175-1191, 2010.

[8] Binder JC. "Global Project Management: Communication, Collaboration and Management across Borders". Gower Publishing, 2007.

[9] Pichler H. "Be successful, take a hostage or outsourcing the outsourcing Manager" in Proc. Second IEEE International Conference on Global Software Engineering, 2007, pp.156-161.

[10] Komi-Sirviö S, Tihinen M. "Lessons Learned by Participants of Distributed Software Development". Journal Knowledge and Process Management, 12 (2), pp.108 -122, 2005.

[11] Kraut RF. and Streeter LA. "Coordination in Software Development". Communications of the ACM, 38(3), 69-81, 1995.

[12] Lamersdorf A, Münch J. "TAMRI: A Tool for Supporting Task Distribution in Global Software Development Projects" in Proc. Fourth IEEE International Conference onGlobal Software Engineering, 2009, pp. 322-327.

[13] Herbsleb JD., Mockus A. "An Empirical Study of Speed and Communication in Globally-Distributed Software Development". IEEE Transactions on Software Engineering, 29(6), 2003.

[14] Smite D, Moe NB. "Understanding a Lack of Trust in Global Software Teams: A Multiple-Case Study". In Proc. Of International Conference on Product Focused Software Development and Process Improvement PROFES, 2007, pp.20-34.

[15] Espinosa JA, Carmel E. "Modeling Coordination Costs Due to Time Separation in Global Software Teams". International Workshop on Global Software Development, 2003.

[16] Krishna S, Sahay S, Walsham G."Managing cross-cultural issues in Global Software Outsourcing". Communications of the ACM, 47(4), pp. 62-66, 2004.

[17] Portillo-Rodríguez, J. "Tools used in Global Software Engineering: A systematic mapping review". Information and Software Technology, (54)7, pp. 663-685, 2012.

[18] Martignoni R. "Global sourcing of software development-a review of tools and services" in Proc. Global Software Engineering, Fourth IEEE International Conference, 2009.

[19] Portillo-Rodríguez J. "Tools to support global software development processes: a survey". In Proc. Global Software Engineering (ICGSE), 5th IEEE International Conference, 2010.

[20] Lanubile F, Ebert C, Prikladnicki R, Vizcaíno A. "Collaboration tools for global software engineering". IEEE software 2, pp. 52-55, 2010.

[21] DOI=http://intland.com/codebeamer/features/ (Retrieved 03/25/2016)

[22] DOI=http://maven.apache.org/ (Retrieved 03/25/2016)

[23] DOI=http://trac.edgewall.org/ (Retrieved 03/25/2016)

[24] DOI=http://www.comindwork.com/ (Retrieved 03/25/2016)

[25] DOI=http://www.gatherspace.com/ (Retrieved 03/25/2016)

[26] DOI=http://www.mantisbt.org/ (Retrieved 03/25/2016)

[27] DOI=http://www.rogerripley.com/workspace_activity_viewer/ (Retrieved 03/25/2016)

[28] DOI=http://www.teamness.com/ (Retrieved 03/25/2016)

[29] DOI=https://se.cs.toronto.edu/drproject/All/wiki/DrProject (Retrieved 03/25/2016)

[30] DOI=https://www.activecollab.com/ (Retrieved 03/25/2016)

[31] DOI=https://www.assembla.com/home (Retrieved 03/25/2016)

[32] DOI=https://www.atlassian.com/software/jira/ (Retrieved 03/25/2016)

[33] DOI=https://www.bugzilla.org/ (Retrieved 03/25/2016)

[34] De Lucia A, Fasano F, Scanniello G, Tortora G. "Enhancing collaborative synchronous UML modelling with fine-grained versioning of software artifacts". Journal of Visual Languages \& Computing, 18(5), pp. 492-503, 2007.

[35] Froehlich J. and Dourish P. "Unifying Artifacts and Activities in a Visual Tool for Distributed Software Development Teams" in Proc. 26th International Conference on Software Engineering (ICSE'04), 2004.

[36] Garousi V, Leitch J. "IssuePlayer: An extensible framework for visual assessment of issue management in software development projects". Journal of Visual Languages \& Computing, 21(3): pp. 121-135, 
2010.

[37] Fonseca S, Souza CD, Redmiles D. "Exploring the Relationship between Dependencies and Coordination to Support Global. Software Development Projects" in Proc. International Conference on Global Software Engineering. Florianopolis, Brazil, 2006, pp. 243-244.

[38] Mak DKM, Kruchten PB. "NextMove: A Framework for Distributed Task Coordination" in Proc. $18^{\text {th }}$ Australian Software Engineering Conference ASWEC 2007, 399-408.

[39] Held M, Blochinger W. "Structured collaborative workflow design". Future Generation Computer Systems, 25(6), pp. 638-653, 2009.

\section{Authors' Profiles}

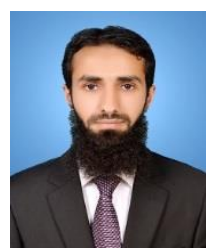

Hafiz Anas Bilal is a citizen of Islamabad, Pakistan. He is a graduate research fellow at Department of Computer Science, COMSATS Institute of Information Technology, Islamabad, Pakistan. His areas of research include Software Quality Engineering, Software Project Management, and Human Machine Interaction. Currently, he has been working on product design engineering and developing some better interfaces for text-entry in smart devices in Non-English languages. Mr. Bilal is a member of IEEE (Institute of Electrical \& Electronics Engineers), PMI (Project Management Institute) Islamabad Pakistan Chapter, ACM (Association of Computing Machinery), and ACM Special Interest Group on Computer Human Interaction (SIGCHI).

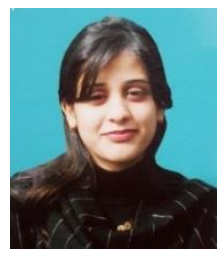

Sunnia Amjad is a citizen of Islamabad, Pakistan. She is a research scholar at Department of Computer Science, COMSATS Institute of Information Technology, Islamabad, Pakistan. Her areas of research include Software Quality Engineering, Software Project Management, and Agile Software Development.

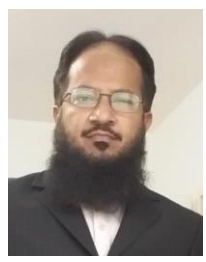

Muhammad Ilyas is an assistant professor in Department of Computer Science and Information Technology at University of Sargodha, Pakistan. He has received his Master degree in Software Project Management in 2004 from National University of Computer and Emerging Sciences, Lahore and a Doctor of Informatics degree from Johannes Kepler University, Linz Austria in 2010. His research interests include Software Engineering, Information Retrieval and knowledge base systems.

How to cite this paper: Hafiz Anas Bilal, Sunnia Amjad, Muhammad Ilyas,"A Comparative Study of Global Software Development Tools Supporting Project Management Activities", International Journal of Education and Management Engineering(IJEME), Vol.7, No.6, pp.32-39, 2017.DOI: 10.5815/ijeme.2017.06.04 